http://jmscr.igmpublication.org/home/ ISSN (e)-2347-176x ISSN (p) 2455-0450 crossref DOI: https://dx.doi.org/10.18535/jmscr/v8i7.52

\title{
Molecular Classification of Breast Carcinoma by Immuno-histochemical Analysis: A Tertiary Cancer Hospital Outcome in Bangladesh
}

\author{
Authors
Dr Md. Rassell ${ }^{1}$, Dr K. M. Shaiful Islam², Dr Anindita Paul ${ }^{3}$, Dr Shaila Parveen ${ }^{4}$, Dr Zillur Rahman Bhuiyan ${ }^{5}$

${ }^{1}$ Assistant Professor, Department of Surgery, Bangabandhu Sheikh Mujib Medical University (BSMMU), Dhaka, Bangladesh

${ }^{2}$ Resident Surgeon, Department of Pediatric Surgery, Dhaka Medical College Hospital, Dhaka, Bangladesh

${ }^{3}$ Register, Department of Surgery, Holy Family Red Crescent Medical College \& Hospital, Dhaka, Bangladesh

${ }^{4}$ Assistant Professor, Department of Surgery, Bikrampur Bhuiyan Medical College \& Hospital, Bangladesh

${ }^{5}$ Associate Professor, Department of Oncology, Bangabandhu Sheikh Mujib Medical University (BSMMU), Dhaka, Bangladesh

Corresponding Author

Dr Md. Rassell

\begin{abstract}
Background: Carcinoma of the breast is a heterogeneous disease \& the most common malignancy in women. The type of carcinoma determined by the involvement of specific cells in the breast that are affected. In Situ breast cancer starts in ductal \& lobular epithelium having no penetration beyond the basement membrane. Invasive or infiltrating breast cancer goes beyond the basement membrane \& infiltrate surrounding breast tissue.
\end{abstract}

Objective: The objective of this study was to identify the subtype of breast carcinoma by immunehistochemical analysis.

Materials \& Method: This cross-sectional study was conducted in the department of surgical oncology, in a tertiary cancer hospital, Dhaka, Bangladesh from March 2015 to April 2016. 121 admitted patients were finalized for the study. Immuno-histochemical staining was performed to classify the subtypes of breast carcinoma.

Results: The mean age of the patients was 42.85(₫9.6). Out of 121 patients, $98.34 \%$ were breast lump, $27.27 \%$ nipple discharge and 52\% were upper outer quadrant lump. Among the total patients, Luminal A type was highest 38(31.4\%), TNBC 37(30.54\%), HER2 was 26(21.48\%), Luminal B type was 16(13.22\%) and $4(3.3 \%)$ as others. According to the molecular classification, well-differentiated tumors, Luminal A, Luminal B, TNBC, HER2, and other observed in 7, 3, 11, 4 and 0 cases and in moderately differentiated tumors Luminal A, Luminal B, TNBC, Her2, and others were observed in 28, 9, 6, 3, and 0 cases. In poorly differentiated tumors Luminal A, Luminal B, TNBC, Her2, and others observed in 3, 4, 20, 19, and 4 cases. Conclusion: The most common tumor subtype is the Luminal A tumors, followed by triple-negative tumors. Luminal $A$ and triple-negative tumors were found to be linked with increased frequency of lobular carcinomas. The HER2-positive and triple-negative tumors were associated with an increased frequency of large tumor size and poorly differentiated carcinomas as well as a more aggressive manifestation of cancer.

Keywords: Molecular sub-type, Immuno-histochemistry (IHC), breastcarcinoma (BC). 


\section{Introduction}

Carcinoma of the breast is the most common malignancy in women and is second only to lung cancer as a cause of cancer deaths. ${ }^{1}$ Variations in gene expression patterns in breast tumors have been identified by using complementary DNA microarray technology which defines several different molecular subtypes. ${ }^{2}$ DNA microarray technology is very expensive and cannot be used on formalin-fixed, paraffin-embedded samples. Recent findings indicate that Immunohistochemical (IHC) protein expression profiles are surrogates for intrinsic gene-derived expression profiles defining molecular subtypes of breast cancer. ${ }^{3}$ Molecular subtyping is crucial because these subtypes show striking differences with regard to patient characteristics, clinic pathological features, treatment response, and outcome. ${ }^{1}$ In this study, we grouped our cases based on IHC markers into four subtypes:- i) Luminal A: Estrogen Receptor (ER) and/or Progesterone Receptor (PR) positive and Human Epidermal Growth Factor Receptor 2 (HER2) negative ii) Luminal B: ER and/or PR positive and HER2 positive iii) HER2/neu-amplification/ Enriched: ER and PR negative and HER2 positive iv) TNBC: ER, PR, and HER2 all negative. Worldwide, breast cancer is the most prevalent cancer as well as the most common female neoplasm accounting for $11.7 \%$ of all cancers in Bangladesh. ${ }^{4}$ According to the world cancer report, more than one million cases occur worldwide each year, and $45 \%$ of these are in developing countries. ${ }^{5}$ The incidence of breast cancer is increasing in most countries but the outcome is now much better in the western world. The five-year survival rates are over $70 \%$ in most of them although racial differences still exist. ${ }^{6}$ This reduction in the morbidity and mortality rates of breast cancer in developed countries has been due to increasing early detection by way of mass screening as well as improved targeted therapy. ${ }^{5}$ In South Asia, it is estimated that each year, 76,000 women die of breast cancer. ${ }^{7}$ In Bangladesh, there is no national cancer registry but estimate an annual new breast cancer case burden of 30,000 women. It is projected that global breast cancer cases will grow from 1.4 million in 2008 to over 2.1 million cases in $2030 .^{8}$ There have been unresolved advances in breast cancer controlling leading to earlier detection of disease and the development of more effective treatments resulting in significant declines in breast cancer deaths and improved outcomes for women living with the disease, over the last few decades. ${ }^{9}$ Breast cancer is no longer seen as a single disease but rather a multifaceted disease comprised of distinct biological subtypes with diverse natural history. It varied spectrum of clinical, pathological, molecular features with different prognostic and therapeutic inferences. Regarding the definitive prognostic/predictive analysis has yet to be reached, but significant progress continues to be made in the ongoing search for a specific, rigorous, and reproducible method of identifying successful treatment algorithms utilizing biological markers. So it can be stated that Breast cancer (BC) is a heterogeneous disease with several classification systems. ${ }^{10} \quad$ Clinico-pathological tumor characteristics cannot explain solely the cellular heterogeneity and genetic complexity of breast carcinomas.8The human breast tumor molecular biology can be better explained by the newly discovered specific molecular subtypes. These subtypes have had an impact on breast cancer patient prognosis and clinical care. However, alternatively, a large fraction of breast tumors approaching $35 \%$ in some collections cannot be assigned to one or another molecular subtype. ${ }^{11}$ Breast cancer cannot be viewed as a single clinicpathological entity. The taxonomy of breast cancer shows several classifications like histopathological, biological and molecular. The two major histopathological classes are invasive ductal carcinoma (IDCS) not otherwise specified (NOS) or invasive lobular carcinoma. According to receptor status, biological classifications of breast cancer are introduced. The peculiar 'classification' of breast cancer that may be best 
seen as a kind of working formulations for clinical use included three main classes. They are 1) Tumor considered to be highly endocrine responsive, 2) Tumor not endocrine responsive, 3) Tumor with uncertain endocrine responsiveness. Endocrine treatment is the best therapeutic option for highly endocrine responsive tumors. Cytotoxic drugs (and Trastuzumab in case of Her 2 overexpression) are the treatment modalities of non-endocrine responsive tumors. Chemotherapy, as well as hormone therapy, are effective in the case of ER-positive and Her2 negative disease. ${ }^{7}$ The original molecular classification has been derived from investigations on fresh frozen tissue based on the molecular expression of ER, PR, Her-2, and Ki-67. Breast cancer can be categorized as five majors subtypes associated with different molecular alterations and distinct clinical outcomes including therapeutic response: luminal A, luminal B, Her-2 enriched, TNBC, and basal/normal-like breast cancer. ${ }^{12}$ Following this discovery, additional subgroups of breast cancer were identified such as the interferon-enriched ${ }^{13}$ and the molecular apocrine ${ }^{14}$ subgroups and several subgroups of triple-negative breast cancer. ${ }^{15}$ Molecular characteristics of the luminal A subtype is $\mathrm{ER}+$ and/or PR+, Her-2-and low proliferation rate, while the luminal $\mathrm{B}$ subtype is characterized by ER+ and/or PR+, Her-2+ and high proliferation rate. Her-2+ subtype characteristics are ER/PR and Her-2+ expression; meanwhile, the triple negative-basal-like subtype is characterized by negative expression of ER/PR and Her-2. Sixty percent of breast cancers are luminal subtype cancers arising from luminal epithelial cells that lined the duct of the mammary gland. The luminal subtypes of breast cancer tend to have a better prognosis compared with the nonluminal subtype because the luminal subtype is a hormone receptor-positive. Therefore, it is more sensitive to the hormone therapy approach. Her$2+$ and triple-negative/basal-like molecular subtypes arise from the basal cell of the mammary gland. These subtypes of breast cancer have a fairly poor prognosis and more prone to early and frequent recurrence and metastasize. Prognosis of Her-2+ subtype is better compared with a triplenegative/basal-like subtype. In 2007, a new intrinsic subtype was described, the claudin-low subtype (CL), through the combined analysis of murine mammary carcinoma models and human breast cancer. ${ }^{16}$ These subtypes represent $6 \%$ of breast cancer samples analyzed (13/232). Notably, the molecular subtypes display highly significant differences in the prediction of overall survival, as well as disease-free survival with the basallike/triple-negative (ER-/PR-/ErbB2-) subtype having the shortest survival. ${ }^{11}$ The triple-negative phenotype has been associated with a higher rate of recurrence and distant metastasis, poorer Nottingham prognostic index, and a higher frequency of spinal cord and meninges, brain, liver, and lung metastases compared with other types of breast cancer. The recent identification of the molecular subtypes of breast cancer has begun to address the ability to predict response to newer targeted therapies. Several intrinsic molecular subtypes of breast cancer have been identified by several studies that were later confirmed and classified as: basal-like, ErbB2+, normal breastlike, luminal subtype $\mathrm{A}$ and luminal subtype. ${ }^{11}$ More recently, a new subtype classified as "claudin-low" has also been identified. ${ }^{17}$ Notably, the molecular subtypes display highly significant differences in the prediction of overall survival, as well as disease-free survival with the basallike/triple-negative (ER-/PR-/ErbB2-) subtype having the shortest survival. ${ }^{11}$ Furthermore, this molecular classification was able to stratify the $\mathrm{ER}+$ population into several subtypes that, again, demonstrated a difference in patient survival. Though clinical assessment of IDC utilizes ER, PR and ErbB2 status, these markers did not allow separation of the two distinct ER+ subtypes (i.e., Luminal A and Luminal B) that have very different clinical outcomes, but it is significant. ${ }^{11}$ 


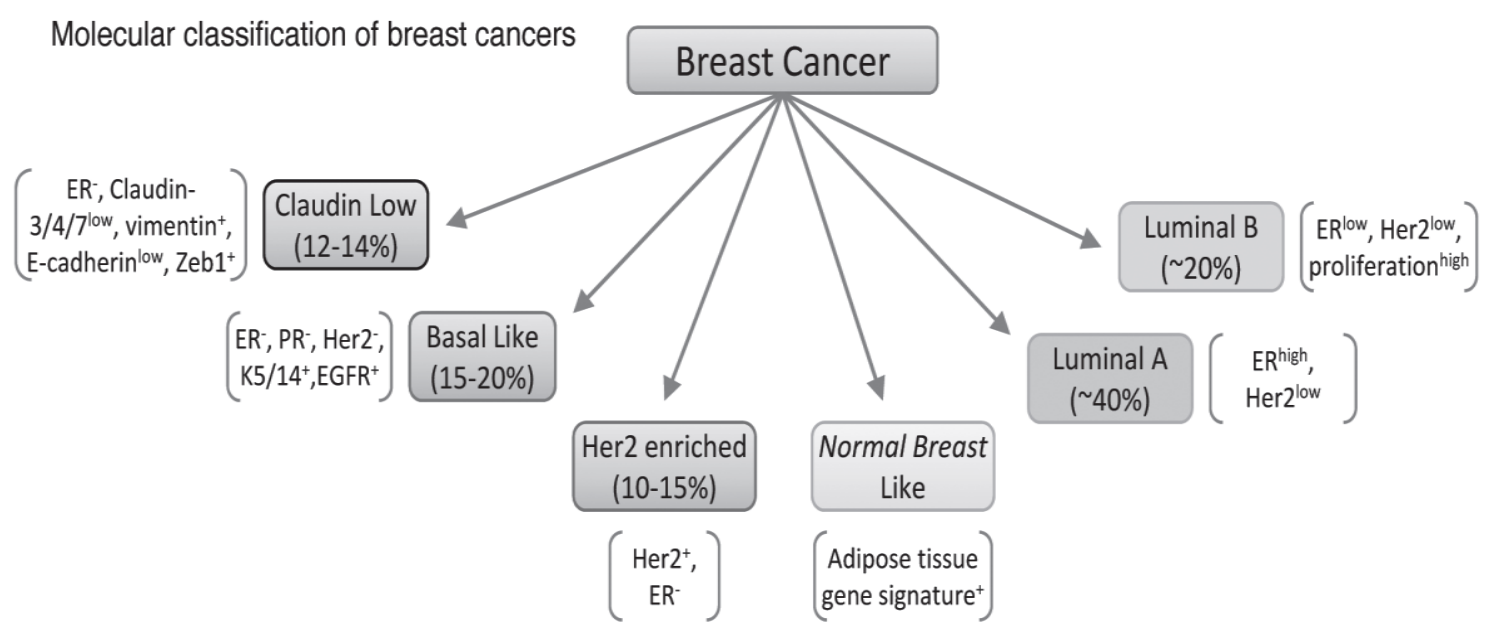

Figure I: Molecular classification of breast cancer. Sorlie T et al. $2003^{8}$

The utility of this new molecular classification to predict outcomes has raised hopes of its adaptation in clinical practice; however, routine use of microarray analysis or genome sequencing is still cost-prohibitive. To overcome this obstacle, investigators narrowed down a 50-gene signature that can effectively differentiate the molecular subtypes using quantitative real-time PCR (qRTPCR). A major benefit of improved risk stratification will be the identification of patients for whom the benefits of neoadjuvant therapy outweigh the risks.

\section{Materials \& Mathod}

This cross-sectional study was conducted in the department of surgical oncology, in a tertiary cancerhospital, Dhaka, Bangladesh during the period from March 2015 to April 2016. Maintaining proper inclusion and exclusion criteria 121 admitted breast cancer patients of a tertiary cancer hospital, Dhaka during the study period were finalized as the study population. According to the inclusion criteria, only histopathologically proven breast cancer patients admitted for surgical treatment were included in this study. On the other hand, according to the exclusion criteria of this study patient who did not wish to be admitted in the study, patients with recurrence and patients with distant metastasis were excluded from the study. In this study, the dependent outcome variable was diagnosed case of breast cancer and the independent variables were age at diagnosis, histological types, histological grades, pathological tumor size, pathological axillary lymph node status, and different molecular subtypes profile-Luminal A, Luminal B, Her-2 enriched, normal-like and TNBC. The operational definitions as in the table I was considered for our study.

Table 1: Operational definition of subtype's breast cancer. ${ }^{18}$

\begin{tabular}{|c|c|c|}
\hline Intrinsic subtypes & Characteristics & Phenotype \\
\hline Luminal A & $\begin{array}{l}\text { High level expression of ER and ER-associated genes, associated with a } \\
\text { favorable clinical outcome. Similar expression than the luminal } \\
\text { epithelium of the breast. }\end{array}$ & ER+ and/or PR+; HER2-, low Ki-67. \\
\hline Luminal B & $\begin{array}{l}\text { Low level expression of ER and ER-associated genes, associated with a } \\
\text { higher tumor cell proliferation rate and a worse clinical outcome } \\
\text { compared to the luminal A subtype. }\end{array}$ & ER+ and/or PR+; HER2+, high Ki-67. \\
\hline HER-2 Enriched & $\begin{array}{l}\text { High level expression of HER2 and GRB7, associated with a poor } \\
\text { outcome before the era of HER2-targeted agents. }\end{array}$ & ER-,PR-, and HER2+ \\
\hline Normal-like & $\begin{array}{l}\text { Similar expression compared to normal breast, suspicious for normal cell } \\
\text { contamination. }\end{array}$ & $\begin{array}{l}\text { Negative for all main markers (ER-, PR-, } \\
\text { HER2-, cytokeratin 5/6- and EGFR-). } \\
\text { Expression of CK8/18. Claudin-low }\end{array}$ \\
\hline $\begin{array}{l}\text { Tripple-negative } \\
\text { (TNBC) }\end{array}$ & $\begin{array}{l}\text { Lack the expression of claudin proteins that are implicated in cell-cell } \\
\text { adhesion, but high expression of EMT and putative stem cell markers, } \\
\text { associated with ER and HER } 2 \text { negativity but low in basal cytokeratin } \\
\text { expression }\end{array}$ & ER-, PR-, HER2-, and/or cytokeratin 5/6+ \\
\hline
\end{tabular}


There was minimum physical, psychological, social, and legal risk during taking a history, physical examination, and investigations. A proper safety measure was taken in every step of the study. Only the researcher was allowed to access the collected data. Ethical clearance was obtained from the Institutional Review Board (IRB) of NICRH to undertake the current study. According to the Helsinki declaration for medical research involving human subjects 1964 , all the patients were informed about the study design, the underlying hypothesis, and the right of the participants to withdraw themselves from the research at any time, for any reason. Informed written consent was obtained from each subject who voluntarily gave consent to participate in this study. Strict confidentiality and security of data related to the patient were maintained. The presentation of data and information related to the patient was documented anonymously. The data analysis was completed on the subjects who complete the study according to the protocol after the recruitment of subjects with valid informed consent. There was not any additional risk or safety concern due to the research process to either patient or researcher. There was not any potential conflict of interest in this study and an entirely an academic research project. Samples of this study were chosen using a consecutive sampling method. Thorough histories were taken and physical examination was done of admitted patients. After surgery from the pathology department histopathology report and tissue, the block was collected that had been sent for immunohistochemistry examination. All relevant data like patients' disease profiles, staging, Histopathology reports, IHC reports were collected, compiled in the datasheet. The results were analyzed by Excel software. A student's ttest was done for data analysis. Samples were stained histologically with Hematoxylin Eosin to determine histological grade and lymph node status. Histological grade of cancer was grouped into a low, moderate, and poor grade based on the Elston and Ellis criteria. ${ }^{19}$ Lymph node status was classified into negative lymph node metastasis, tumor metastasis to $\leq 3$ lymph nodes and tumor metastasis to $>3$ lymph nodes. Cancer Staging was classified into stages I, II, and III. Tumor size was categorized into $<2 \mathrm{~cm}, 2-5 \mathrm{~cm}$, and $>5 \mathrm{~cm}$ which was determined by gross pathological examination. Patient age was grouped into $\leq 50$ and $>50$ years old. Immuno-histochemical (IHC) staining was performed to classify the molecular subtypes of breast cancers. Normal breast tissue was used as a positive control; meanwhile, a negative control was obtained by omitting the primary antibodies. ER/PR expression is considered positive if it is stained in $>1 \%$ of tumor nuclei of the total tumor cells. ${ }^{20}$ Her-2 positive cancers if they were scored $3+{ }^{21}$ Cancers with Her-2 scored 2+ (indeterminate) will be considered negative for Her-2 in the absence of fluorescent in situ hybridization (FISH) or $\mathrm{CISH}$ data. High ki-67 rate is positive if $>14 \%$ of cancer cells show positive nuclear staining. ${ }^{22}$ Characteristics of breast cancer of luminal A subtype are ER and or PR+, Her-2-, and low Ki67 proliferation rate. Luminal $\mathrm{B}$ cancer subtype characteristics are ER and or PR+, Her-2+, and high ki-67 rate. Her-2+ molecular subtype will show ER and PR negative, but positive Her-2 expression. Triple-negative/basal-like cancer subtype is characterized by ER/PR and Her-2 negative staining. Several clinic-pathological features will be analyzed using Pearson's ChiSquare test. A p-value of $<0.05$ was considered statistically significant. After collection, data were entered into a personal computer and were edited, analyzed, plotted, and was in graphs and table.

\section{Results}

In this study out of total 121 breast cancer patients, 48 (39.67\%) patients belonged to the age of 31-40 years, followed by 41-50 years age group by $43(35.53 \%), 51-60$ years age group were $14(11.57)$, age group $\geq 30$ years were $12(9.83 \%)$ and the elderly patient's age group $>60$ years were lowest in number $4(3.4 \%)$. The mean age was 42.85 ( \pm 9.6$)$ years. Maximum patients of this 
study were qualified up to SSC 41(33.88\%) followed by primary level 40(33.05\%), HSC $35(28.92 \%)$ and finally, $4(4.15 \%)$ were illiterate. In this study, $69(57 \%)$ patients were in the premenopausal stage and rest $52(43 \%)$ patients were in the post-menopausal stage. Almost $98.34 \%$ of patients had breast mass, $27.27 \%$ of patients had associated features of nipple discharge with breast lump pain were in $15.7 \%$ and other complications cases were $9.09 \%$. This study manifests that Luminal A 38 (31.4\%), luminal B 16 (13.22\%), TNBC 37 (30.57\%), Her2 enriched 26 (21.48\%), other $4(3.3 \%)$ out of 121 respondents. Other features denoted as nipple retraction, deviation, ulceration, etc. In this study, the commonest site of the lump was upper outer quadrant $(43.69 \%)$ followed by the lower outer quadrant (31.93\%). The considerable figure of the lump was also seen in the lower inner quadrant $(11.76 \%)$ and central zone $(8.4 \%)$. The lowest number of patients revealed in the upper inner quadrant $(4.2 \%)$. The baseline characteristics of tumor-like staging, grading, histopathological status, receptor status and molecular subtypes. Among the molecular subtypes, $31.4 \%$ tumor was luminal A type followed by $30.57 \%$, tumor with Tripple Negative Breast Cancer (TNBC). A considerable percentage of tumors belong to Her2 enriched molecular subtypes $(21.48 \%)$ on the contrary
Luminal B subtypes. In this study, we found the relation of tumor size ( $\mathrm{T}$ staging) and molecular subtypes of breast cancer. In $\mathrm{T}$ staging $\mathrm{I}$ the Luminal A, Luminal B TNBC, Her2 enriched were found in $3,1,1,1$ and 0 cases respectively. In $\mathrm{T}$ staging 2 the Luminal A, Luminal B TNBC, Her2 enriched were found in 24, 10, 31, 18 and 3 cases respectively. On the other hand, In T staging 3 the Luminal A, Luminal B TNBC, Her2 enriched were found in 11, 5, 5, 7 and 1 cases respectively. According to the lymph node status, where the lymph node was present there the Luminal A, Luminal B TNBC, Her2 and others were in $21,6,21,10$ and 0 cases respectively. On the other hand, where the lymph node was absent there the Luminal A, Luminal B TNBC, Her2 and others were in $17,10,16,16$ and 4 cases respectively. According to the grading of the tumor, in a well-differentiated tumor, the Luminal A, Luminal B TNBC, Her2 and others were observed in 7, 3, 11, 4 and 0 cases respectively. Besides these, in moderately differentiated tumors the Luminal A, Luminal B TNBC, Her2 and others were observed in $28,9,6,3$ and 0 cases respectively. On the other hand, in poorly differentiated tumors the Luminal A, Luminal B TNBC, Her2 and others were observed in 3, 4, 20, 19 and 4 cases respectively.

Table 2: Key Outcomes of the Participant Patients $(\mathrm{n}=121)$

\begin{tabular}{|c|c|c|c|}
\hline Variables & $\mathrm{n}$ & $\%$ & $\operatorname{Mean}( \pm \mathrm{SD})$ \\
\hline \multicolumn{4}{|l|}{ Age group of Patients } \\
\hline$\geq 30$ years & 12 & 9.83 & \multirow{5}{*}{$42.85( \pm 9.6)$} \\
\hline $31-40$ years & 48 & 39.67 & \\
\hline $41-50$ years & 43 & 35.53 & \\
\hline $51-60$ years & 14 & 11.57 & \\
\hline$>60$ years & 4 & 3.4 & \\
\hline Base & 121 & 100.0 & \\
\hline \multicolumn{4}{|c|}{ Educational Qualification of Patients } \\
\hline Illiterate & 5 & 4.15 & \\
\hline Primary & 40 & 33.05 & \\
\hline $\mathrm{SSC}$ & 41 & 33.88 & \\
\hline HSC & 35 & 28.92 & \\
\hline Base & 121 & 100.0 & \\
\hline \multicolumn{4}{|c|}{ Patients Menopausal Status } \\
\hline Pre-menopausal stage & 69 & 57.0 & \\
\hline Post-menopausal stage & 52 & 43.0 & \\
\hline Base & 121 & 100.0 & \\
\hline \multicolumn{4}{|l|}{ Patients Clinical status } \\
\hline Mass & 119 & 98.34 & \\
\hline Nipple discharge & 33 & 27.27 & \\
\hline Pain & 19 & 15.7 & \\
\hline Others & 11 & 9.09 & \\
\hline
\end{tabular}




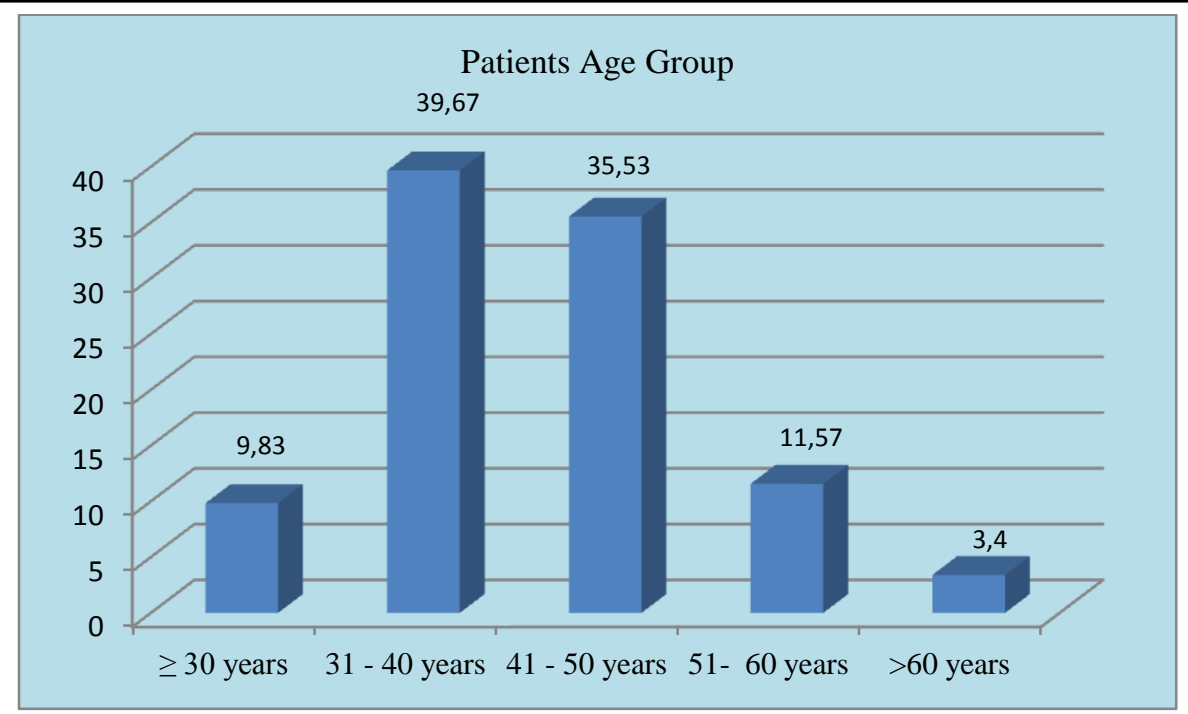

Figure VI: Patients Age Group $(n=121)$

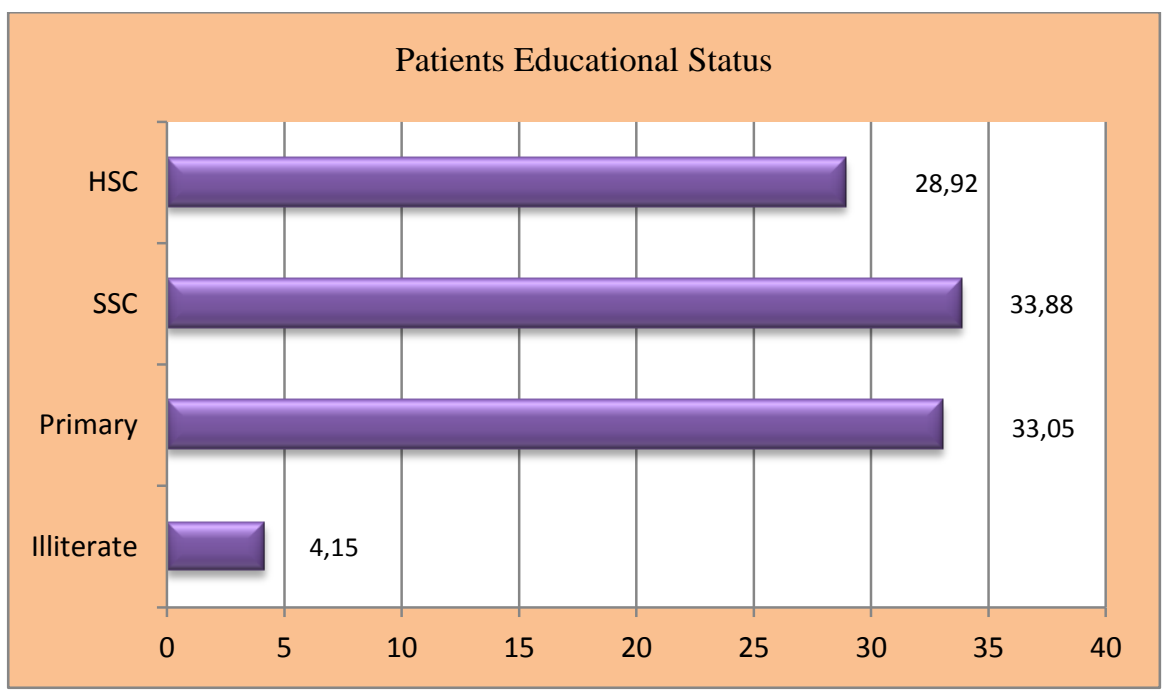

Figure VII: Patients Educational Status $(n=121)$

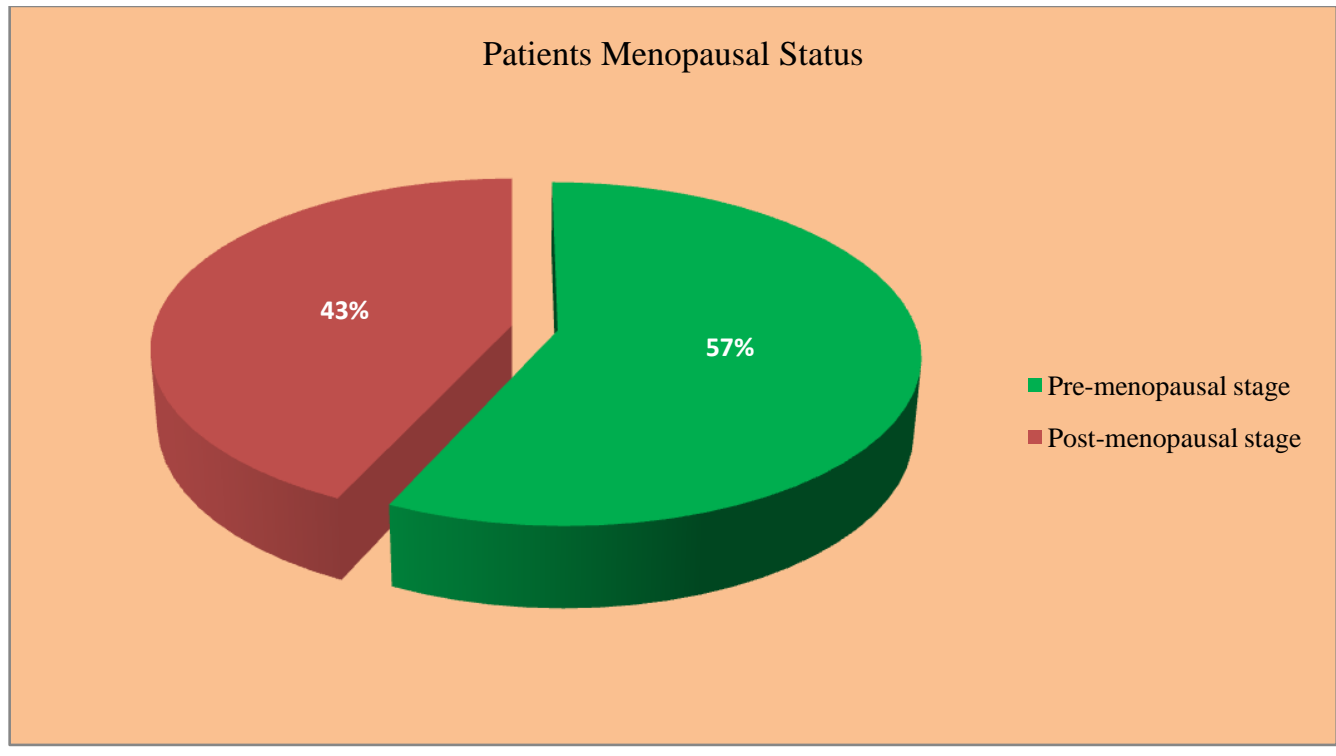

Figure VIII: Patients Menopausal Status (n=121) 


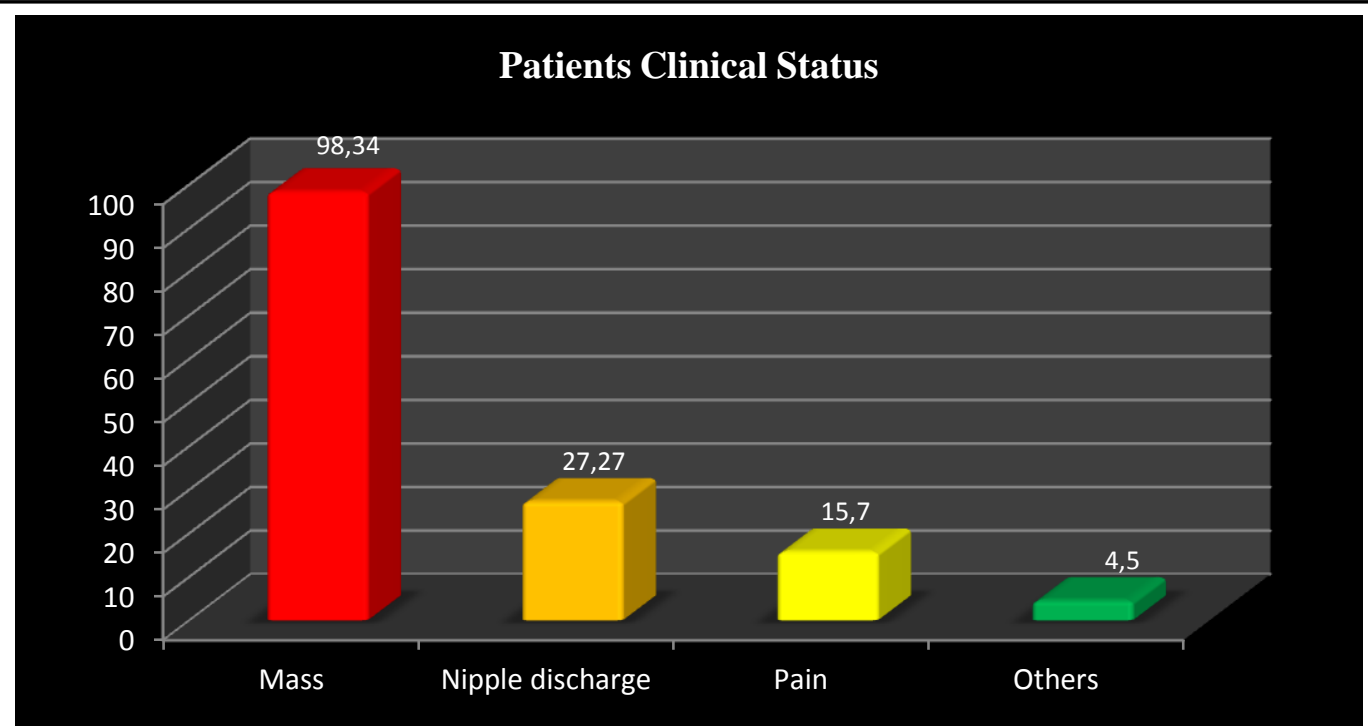

Figure XI: Patients Clinical Status $(\mathrm{n}=121)$

Table 3: Distribution of baseline characteristics $(n=121)$

\begin{tabular}{|c|c|c|}
\hline Variables & $\mathrm{n}$ & $\%$ \\
\hline \multicolumn{3}{|l|}{ Tumor stage } \\
\hline I & 43 & 35.54 \\
\hline II & 68 & 56.20 \\
\hline III & 10 & 8.26 \\
\hline \multicolumn{3}{|l|}{ Cancer Type } \\
\hline Ductal & 88 & 72.73 \\
\hline Lobular & 15 & 12.40 \\
\hline Ductal \& lobular & 9 & 7.44 \\
\hline Inflammatory & 1 & 0.83 \\
\hline Others & 8 & 6.61 \\
\hline \multicolumn{3}{|l|}{ Histological grade } \\
\hline Well differentiated & 25 & 20.66 \\
\hline Moderately differentiated & 46 & 38.02 \\
\hline Poorly differentiated & 50 & 41.32 \\
\hline \multicolumn{3}{|l|}{ Tumor Size } \\
\hline$\leq 2 \mathrm{~cm}$ & 6 & 4.96 \\
\hline $2.1-5 \mathrm{~cm}$ & 86 & 71.07 \\
\hline$>5 \mathrm{~cm}$ & 29 & 23.97 \\
\hline \multicolumn{3}{|l|}{ Lymph node status } \\
\hline Positive & 58 & 47.93 \\
\hline Negative & 63 & 52.07 \\
\hline \multicolumn{3}{|l|}{ Receptor status } \\
\hline $\mathrm{ER}(+)$ & 74 & 61.16 \\
\hline ER (-) & 47 & 38.84 \\
\hline $\mathrm{PR}(+)$ & 71 & 58.68 \\
\hline PR (-) & 50 & 41.32 \\
\hline Her2 (+) & 46 & 38.02 \\
\hline Her2 (-) & 75 & 61.98 \\
\hline \multicolumn{3}{|l|}{ Tumor Subtypes } \\
\hline Luminal A (ER/PR+Her2-) & 38 & 31.40 \\
\hline Luminal B (ER/PR+Her2+) & 16 & 13.22 \\
\hline TNBC (ER/PR-Her2- & 37 & 30.58 \\
\hline Her2 (ER/PR-Her2+ & 26 & 21.49 \\
\hline Others & 4 & 3.31 \\
\hline
\end{tabular}




\section{JMSCR Vol||08||Issue ||07||Page 311-323||July}

Table 4: Baseline characteristics according to tumor subtypes $(n=121)$

\begin{tabular}{|c|c|c|c|c|c|c|}
\hline Variables & $\begin{array}{c}\text { Luminal A } \\
(\mathrm{n}=38)\end{array}$ & $\begin{array}{c}\text { Luminal B } \\
(\mathrm{n}=16)\end{array}$ & $\begin{array}{l}\text { TNBC } \\
(\mathrm{n}=37) \\
\end{array}$ & $\begin{array}{l}\text { Her2 Enriched } \\
(\mathrm{n}=26)\end{array}$ & $\begin{array}{c}\text { Others } \\
(\mathrm{n}=4)\end{array}$ & p-Value \\
\hline Age (years) & $44.86 \pm 10.15$ & $45.37 \pm 10.29$ & $39.21 \pm 9.87$ & $44.07 \pm 7.1$ & $45.75 \pm 5.96$ & $>0.05^{\mathrm{ns}}$ \\
\hline \multicolumn{7}{|l|}{ Tumor Stage } \\
\hline $\mathrm{I}(\mathrm{n}=43)$ & 10 & 13 & 15 & 5 & 0 & \multirow{3}{*}{$<0.05^{\mathrm{s}}$} \\
\hline $\mathrm{II}(\mathrm{n}=68$ & 27 & 2 & 16 & 2 & 2 & \\
\hline $\mathrm{III}(\mathrm{n}=10)$ & 1 & 1 & 6 & 0 & 2 & \\
\hline \multicolumn{7}{|l|}{ Cancer Types } \\
\hline Ductal $(n=88)$ & 29 & 14 & 33 & 10 & 2 & \multirow{5}{*}{$<0.05^{\mathrm{s}}$} \\
\hline Lobular $(n=15)$ & 5 & 1 & 4 & 4 & 1 & \\
\hline Ductal \& lobular $(\mathrm{n}=9)$ & 1 & 1 & 0 & 7 & 0 & \\
\hline Inflammatory $(\mathrm{n}=1)$ & 1 & 0 & 0 & 0 & 0 & \\
\hline Others $(n=8)$ & 2 & 0 & 0 & 5 & 1 & \\
\hline \multicolumn{7}{|l|}{ Histological grade } \\
\hline Well differentiated $(n=25$ & 7 & 3 & 11 & 4 & 0 & \multirow{3}{*}{$>0.05^{\mathrm{ns}}$} \\
\hline Moderately differentiated $(n=46)$ & 28 & 9 & 6 & 3 & 0 & \\
\hline Poorly differentiated $(\mathrm{n}=50)$ & 3 & 4 & 20 & 19 & 4 & \\
\hline \multicolumn{7}{|l|}{ Tumor Size } \\
\hline$\leq 2 \mathrm{~cm}(\mathrm{n}=6)$ & 3 & 1 & 1 & 1 & 0 & \multirow{3}{*}{$<0.05^{\mathrm{s}}$} \\
\hline $2.1-5 \mathrm{~cm}(\mathrm{n}=86)$ & 24 & 10 & 31 & 18 & 3 & \\
\hline$>5 \mathrm{~cm}(\mathrm{n}=29)$ & 11 & 5 & 5 & 7 & 1 & \\
\hline \multicolumn{7}{|l|}{ Lymph node status } \\
\hline Positive $(\mathrm{n}=58)$ & 21 & 6 & 21 & 10 & 0 & \multirow{2}{*}{$>0.05^{\mathrm{ns}}$} \\
\hline Negative $(n=63)$ & 17 & 10 & 16 & 16 & 4 & \\
\hline
\end{tabular}

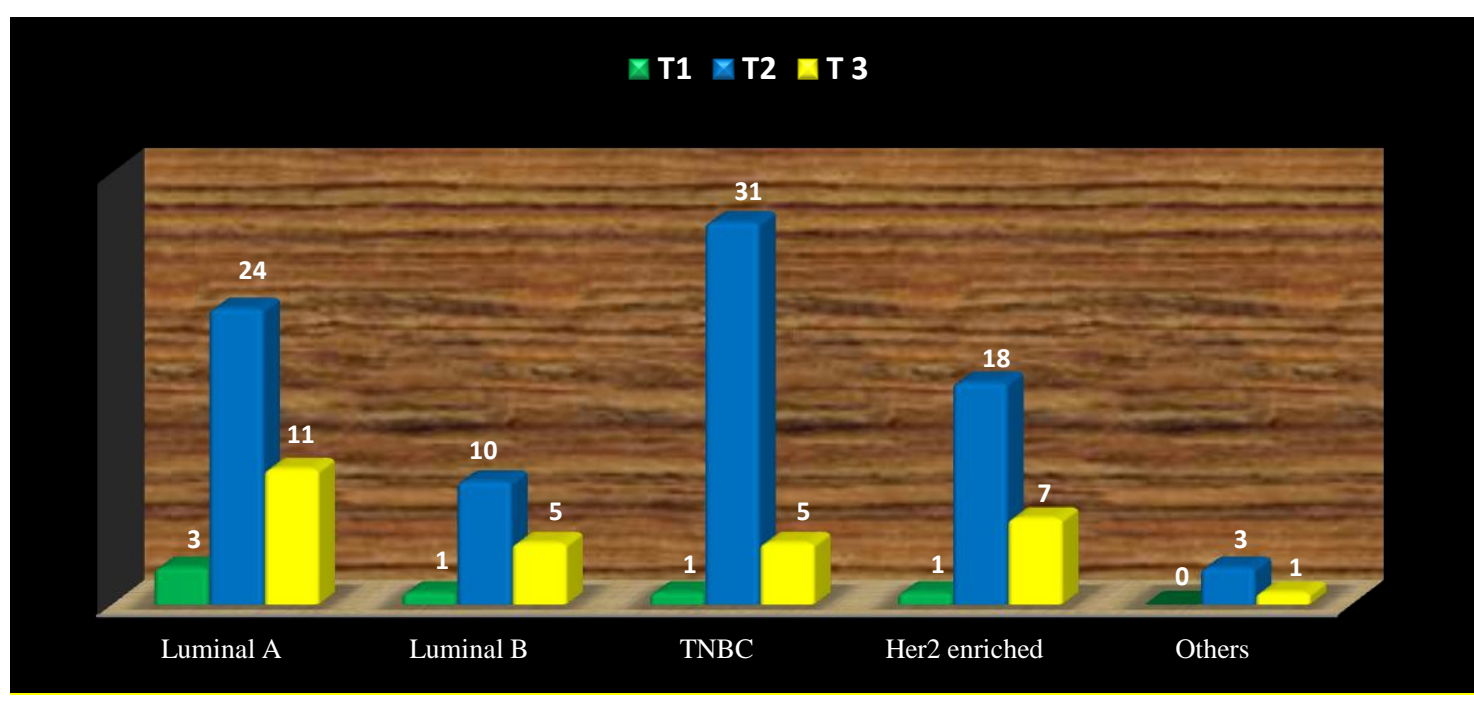

Figure X: Molecular subtypes according to T staging $(n=121)$

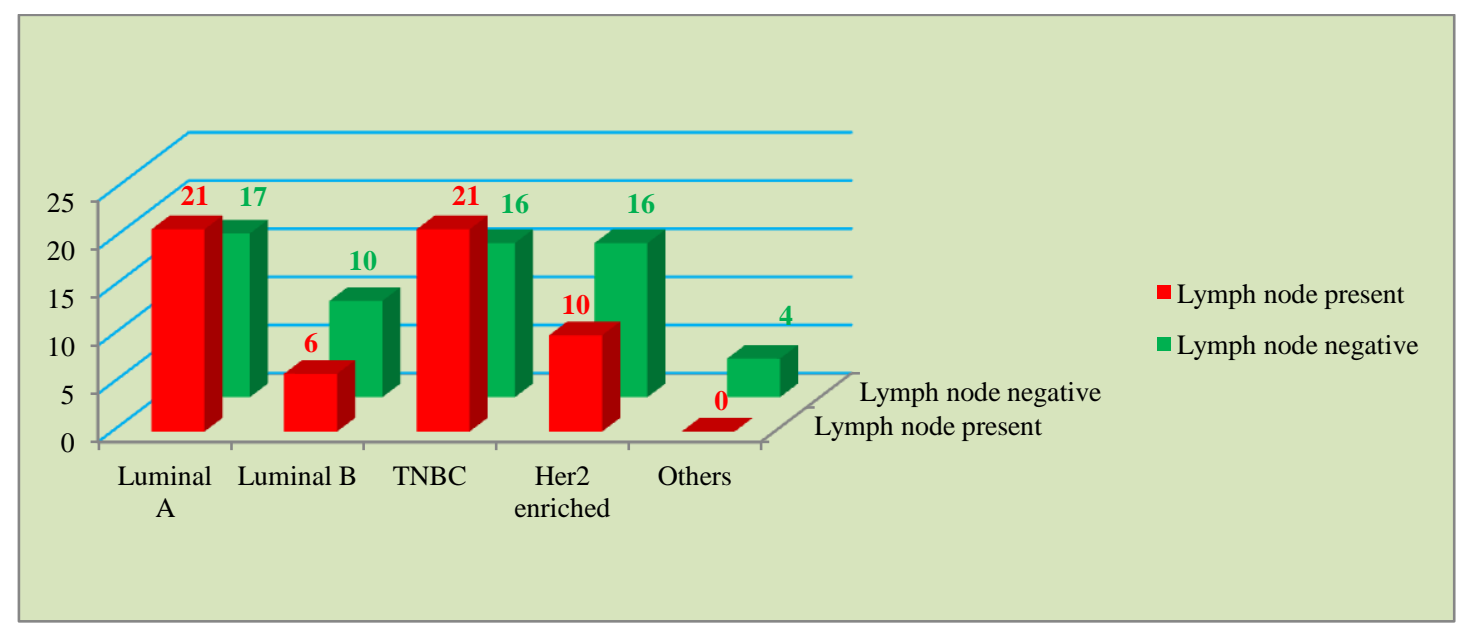

Figure XI: Distribution of molecular subtype in relation to lymph node status $(n=121)$ 


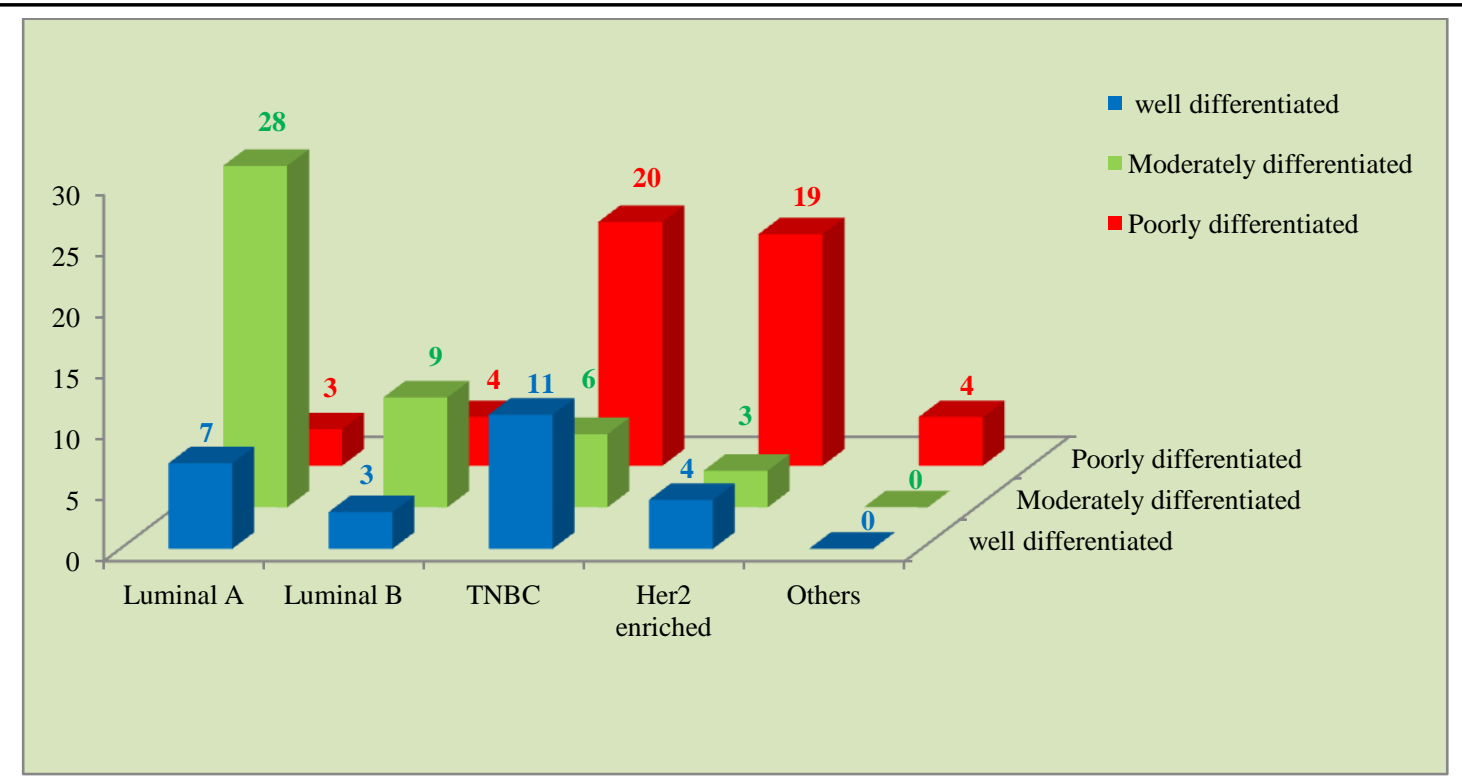

Figure XII: Distribution of molecular subtype in relation to grading of tumor $(n=121)$

\section{Discussion}

In this study, it was found that Luminal a 38 (31.4\%), Luminal B $16(13.22 \%)$, TNBC 37 (30.57\%), Her2 enriched 26(21.48\%), other $4(3.3 \%)$ were observed out of 121 respondents. Breast cancer is a multifaceted disease comprised of distinct biological subtypes with diverse natural history which are increasingly recognized as presenting a multidimensional spectrum of clinical, pathological, and molecular features with different prognostic and therapeutic implications. ${ }^{23}$ This study provides a comprehensive characterization of a series of breast cancer from the point of view of molecular classification. This study revealed statistically significant differences in clinical and pathological features of different sub-classification of breast cancer. These subtypes, however, be complemented with the many other important traditional prognostic variables for the individual such as age, tumor size, lymph node status, comorbidity, etc. The commonest way of molecular subtyping is microarray way of molecular subtyping the study place had no such a facility; so the optional way of molecular subtyping had to be used. Immunohistochemistry classification both ER/PR and Her2 status provides predictive and therapeutic information not achievable alone. Prior sub-classifications separating breast cancer into one of two categories based on ER expression is less discriminatory in terms of prognosis, and the additional sub-classification based on Her2 expression provides enhanced and important therapeutic guidance. Breast cancer has also sometimes been dichotomized into triple negativity or others. ${ }^{24}$ determining the molecular subtype of breast cancer by IHC markers has some limitations. ${ }^{25}$ There is no consensus on how to define exactly the basal-like breast cancer and overlap categories exist. Although a majority of basal-like breast cancers are triple-negative; ER or Her2 expression has been reported in about $15 \%$ $45 \%$ of the basal-like cancers. ${ }^{12}$ Therefore the obvious limitation of using IHC to define subtypes is that it might result in the microclassification bias of some tumors. This study manifests that luminal A 38 (31.4\%), luminal B 16(13.22\%), TNBC 37(30.57\%), Her2 enriched $26(21.48 \%)$, other $4(3.3 \%)$ out of 121 respondents. In the above-mentioned results, Luminal A was found the highest in number whereas Luminal B ranked the 4th among the 5 molecular subtypes. Luminal A and Luminal B express mainly the lower and higher grade estrogen positivity. At the most basic level, the luminal subtypes share expression of estrogen receptor (ER)-related genes and have better overall survival than the Her2-related and the 
basal-like subtypes, which are typically (but not uniformly) ER-negative. ${ }^{12}$ Luminal cancers express hormone receptors and are lower grade while the HER2 subtypes overexpress Her2 gene products and are higher grade. Luminal B cancers have a worse prognosis than luminal. Cancers; often have lower expression levels of hormone receptors, higher Nottingham grade, and higher proliferative rates; and can be Her 2 positive. ${ }^{26}$ There is clinical interest in distinguishing the luminal B cancers from luminal A cancers because they may be a subset of ER-positive cancers that derive benefit from more aggressive therapy. ${ }^{27}$ Here the Her2 enriched group patients were found $21.48 \%$ of the total population. The study in Shanghai ${ }^{28}$ and Taiwan showed separately the figure of Here 2 in their studies was $31 \%$ and $26 \%$ respectively. But a Taiwan study report was found almost similar to our study where the Her2 enriched molecular subtype patients were found in the case of $21 \%$ cases. These variations are may be due to underreporting of our patients, skill, and expertise variation from the laboratory to a laboratory in different centers of the world. Clinically, Luminal A has the characteristics of common occurrence ${ }^{29}$ Luminal B tumor that may benefit from taxanes in the adjuvant settings. ${ }^{30}$ So, a vivid picture of subsequent treatment response so, it can be predicted from this study that 38 patients out of 1212 of this study may show recurrence whereas $16(13.22 \%$ ) out of 121 of this study may respond better with adjuvant taxanes. The independent prognostic role of PR expression irrespective of ER has been a subject of great debatable as revealed by the report from the ATAC adjuvant a large worldwide trial comparing the effectiveness of tamoxifen with that of the aromatase inhibitor anastrozole, showing overall that patients with $E R+/ P R+$ tumors had a lower repetition rate than those with ER tumors. ${ }^{31}$ The observation from the same study that patients with ER tumors respond nearly as well to anastrozole as those with $\mathrm{ER}+/ \mathrm{PR}+$ tumors suggests that ER gesturing pathway is functional in many ER tumors., unswerving with the well-known fact that the PR gene is controlled by the estrogen pathway. Studies that have been classified as using more than 4 subtypes are plagued by these controversies and those inherent in small sample size and multiplicity of variables. ${ }^{32}$

\section{Conclusion}

In this study, it has been revealed that the most common tumor subtype is the Luminal A tumors, followed by triple-negative tumors. Luminal A and triple-negative tumors were found to be linked with increased frequency of lobular carcinomas. The HER2-positive and triple-negative tumors were associated with an increased frequency of large tumor size and poorly differentiated carcinomas as well as a more aggressive manifestation of cancer. Additionally, HER2positive tumors were less frequently observed in carcinoma, in situ. We also observed a strong correlation between lymph node status and molecular subtypes. An in-depth investigation of the risk factors associated with different molecular subtypes of breast carcinoma is to be required. It is also important to investigate the effect of different breast cancer subtypes on the prognosis and survival of the patient. These findings may be helpful in farther studies on similar topics.

\section{References}

1. Kumar V, Abbas AK, Aster JC. Robbins and Cotran Pathologic Basis of Disease, 9th edition, Elsevier. 2015; 1051-1052.

2. Perou CM, Sorlie T, Eisen MB et al. Molecular portraits of human breast tumors. Nature. 2000; 406(6797):747-752.

3. Prat A, Cheang MCU, Martín $M$ et al. Prognostic significance of progesterone receptor-positive tumor cells within immunohistochemically defined luminal a breast cancer. J ClinOncol. 2013; 31(2):203-209..

4. Cancer Registry Report 2008-2010. Published by Department of Cancer Epidemiology, National Institute of Cancer 
Research and Hospital, Published in December 2013, p-11.

5. Stewart BW, Kleihues P (2003), editors. World Cancer report. Lyon: IARC Press.

6. Parkin DM, Bray F, Ferlay J, Pisani P (2005). Global cancer statistics, 2002. CA: a cancer journal for clinicians; 55:74-108.

7. Brown M, Goldie S, Draisma G, Harford J (2006). Health service interventions for cancer control in developing countries in Disease Control Priorities in Developing Countries. Oxford University Press,vol. 2, pp. 569-90.

8. World Cancer Research Fund. Available from: http://www.wcrf.org/ cancer_facts/women-breast-cancer.php/. Accessed March 10, 2016.

9. Glass AG, Lacey JV Jr, Carreon JD, Hoover RN (2007). Breast cancer incidence, 1980-2006: combined roles of menopausal hormone therapy, screening mammography, and estrogen receptor status. J Natl Cancer Inst; 99:1152-1161.

10. Viale G: The current state of breast cancer classification. Ann Oncol 2012, 23 (Suppl 10): x207-x210.

11. Sorlie T, Tibshirani R, Parker J, Hastie T, Marron JS, et al. (2003) Repeated observation of breast tumor subtypes in independent gene expression data sets. Proc Natl AcadSci U S A 100: 8418-8423.

12. Sorlie T, Perou CM, Tibshirani R, et al (2001). Gene expression patterns of breast carcinomas distinguish tumor subclasses with clinical implications. Proc Natl AcadSci USA.; 98:10869-10874.

13. Hu Z, Fan C, Oh DS, Marron JS, He X, Qaqish BF, Livasy C, Carey LA, Reynolds E, Dressler L, Nobel A, Parker J, Ewend MG, Sawyer LR, Wu J, Liu Y, Nanda R, Tretiakova M, Ruiz Orrico A, Dreher D, Palazzo JP, PerreardL, Nelson E, Mone M, Hansen H, Mullins M, Quackenbush JF, Ellis MJ, Olopade OI, Bernard PS, et al (2006). The molecular portraits of breast tumors are conserved across microarray platforms. BMC Genomics, 7:96.

14. Farmer P, Bonnefoi H, Becette V, TubianaHulin M, Fumoleau P, Larsimont D, Macgrogan G, Bergh J, Cameron D, Goldstein D, Duss S, Nicoulaz A-L, Brisken C, Fiche M, Delorenzi M, Iggo R (2005). Identification of molecular apocrine breast tumours by microarray analysis. Oncogene, 24:4660-4671.

15. Lehmann BD, Bauer JA, Chen X, Sanders ME, Chakravarthy AB, Shyr Y, Pietenpol JA (2011). Identification of human triplenegative breast cancer subtypes and preclinical models for selection of targeted therapies. J Clin Invest, 121:2750-2767.

16. Herschkowitz JI, Simin K, Weigman VJ, Mikaelian I, Usary J, Hu Z, Rasmussen KE, Jones LP, Assefnia S, Chandrasekharan S, Backlund MG, Yin Y, Khramtsov AI, Bastein R, Quackenbush J, Glazer RI, Brown PH, Green JE, Kopelovich L, Furth PA, Palazzo JP, Olopade OI, Bernard PS, Churchill GA, Van Dyke T, Perou CM (2007). Identification of conserved gene expression features between murine mammary carcinoma models and human breast tumors. Genome Biol; 8:R76.

17. Prat A, Parker JS, Karginova O, Fan C, Livasy C, Herschkowitz JI, et al (2010). Phenotypic and molecular characterization of the claudin-low intrinsic subtype of breast cancer. Breast Cancer Res; 12:68.

18. ParvinF.Peddi, Matthew J.Ellis, and Cynthia Ma (2012). Molecular Basis of Triple Negative Breast Cancer and Implications for Therapy. Hindawi Publishing Corporation. International Journal of Breast Cancer. Article ID 217185, 7 pages.

19. Tavassoli FA, Devilee P (2003). World Health Organization Classification of Tumours. Pathology and Genetics of Tumours of the Breast and Female Genital Organs. Lyon: IARC Press. 
20. Hammond MEH, Hayes DF, Wolff AC, et al. (2010). American Society of Clinical Oncology/College of American Pathologists Guideline recommendations for immunohistochemical testing of estrogen and progesterone receptors in breast cancer. J Oncol Practice, 6, 15-7.

21. Wolff AC., Hammond EH, Schwartz KL, et al (2007). American Society of Clinical Oncology/College of American Pathologists Guideline Recommendations for human epidermal growth factor receptor 2 testing in breast cancer. Arch Pathol Lab Med, 33, 19-33.

22. Gnant M, Harbeck N, Thomssen C (2011). St Gallen 2011: Summary of the consensus Discussion. Breast Cancer, 6, 136-41.

23. Carey LA, Perou CM, Livasy CA, Dressler LG, Cowan D, Conway K, Karaca G, Troester MA, Tse CK, Edmiston S, Deming SL, Geradts J, Cheang MC, Nielsen TO, Moorman PG, Earp HS, Millikan RC (2006). Race, breast cancer subtypes, and survival in the Carolina Breast Cancer Study. JAMA; 295:24922502.

24. Carey LA, Dees EC, Sawyer L, Gatti L, Moore DT, Collichio F, Ollila DW, Sartor CI, Graham ML, Perou CM (2007). The triple negative paradox: primary tumor chemosensitivity of breast cancer subtypes. Clin Cancer Res; 13:2329-2334

25. Rakha EA, Reis-Filho JS, Ellis IO (2008). Basal-like breast cancer: a critical review. J ClinOncol,; 26:2568-2581.

26. Cheang MC, Chia SK, Voduc D, et al (2009). Ki67 index, HER2 status, and prognosis of patients with luminal B breast cancer. J Natl Cancer Inst.; 101:736-750.

27. Desmedt C, Haibe-Kains B, Wirapati P, et al (2008). Biological processes associated with breast cancer clinical outcome depend on the molecular subtypes. Clin Cancer Res.; 14:5158-5165.
28. Zhao X, Malhotra GK, Lele SM, Lele MS, West WW, Eudy JD, et al (2010). Telomerase-immortalized human mammary stem/progenitor cells with ability to selfrenew and differentiate. Proc Natl AcadSci USA; 107:14146-51.

29. Fan C, Oh DS, Wessels L, Weigelt B, Nuyten DS, Nobel AB, van't Veer LJ, Perou CM (2006). Concordance among gene-expression-based predictors for breast cancer. N Engl J Med; 355:560-569.

30. Hayes DF, Thor AD, Dressler LG, Weaver D, Edgerton S, Cowan D, Broadwater G, Goldstein LJ, Martino S, Ingle JN, Henderson IC, Norton L, Winer EP, Hudis CA, Ellis MJ, Berry DA (2007). Cancer and Leukemia Group B (CALGB) Investigators. HER2 and response to paclitaxel in node-positive breast cancer. $\mathrm{N}$ Engl J Med; 357:1496-1506.

31. Howell A, Cuzick J, Baum M, Buzdar A, Dowsett M, Forbes JF, Hoctin-Boes G, Houghton J, Locker GY, Tobias JS (2005). ATAC Trialists' Group. Results of the ATAC (Arimidex, Tamoxifen, Alone or in Combination) trial after completion of 5 years' adjuvant treatment for breast cancer. Lancet; 365:60-62.

32. Brouckaert O, Pintens S, Van Belle V, Van Huffel S, Camerlynck E, Amant F, Leunen $\mathrm{K}$, Smeets A, Berteloot P, Van Limbergen E, Decock J, Hendrickx W, Weltens C, Van den Bogaert W, VandenBempt I, Drijkoningen M, Paridaens R, Wildiers H, Vergote I, Christiaens MR, Neven P (2009). Short-term outcome of primary operated early breast cancer by hormone and HER-2 receptors. Breast Cancer Res Treat; 115:349-358. 